\title{
Early Literacy Skills and Later Reading and Writing Performance Across Countries: The Effects of Orthographic Consistency and Preschool Curriculum
}

\author{
Marinella Majorano ${ }^{1}$. Tamara Bastianello ${ }^{1}$ (D) Carolina Bodea-Hategan ${ }^{2}$. \\ Patrizia Fantuzzi ${ }^{3}$. Giulia Fontana ${ }^{3}$. Eddy Hoste ${ }^{4}$ Marco Lombardi ${ }^{4}$. An Standaert ${ }^{4}$. \\ Dorina Talas $^{2} \cdot$ Raluca Trifu $^{5} \cdot$ Lisa Vescogni $^{3} \cdot$ Valentina Persici $^{1}$ (D)
}

Accepted: 23 March 2021 / Published online: 14 April 2021

(C) The Author(s) 2021

\begin{abstract}
Background Studies have reported a strong association between children's early literacy skills at preschool and their reading and writing skills at primary school. However, it is unclear whether this association is affected by language and curriculum practices.

Objective The study investigates (i) whether early literacy skills are influenced by orthographic consistency and by preschool curriculum, and (ii) how early skills are related to later literacy skills across countries.

Method Three countries, Italy $(n=73)$, Romania $(n=65)$, and Belgium $(n=109)$ were involved in the study, for a total of 247 children. Language and early literacy in preschool were assessed using a novel assessment tool (the 'Talk'). Early visual-phonological and manual aspects integration were investigated using rapid automatized naming and graphomotor tasks. The children's reading and writing skills nine months later were assessed using standardized tests.

Results Results showed higher early literacy scores for the groups of children speaking languages with more transparent orthographic systems and for the group taking part in preschool activities designed to enhance literacy acquisition. Later reading and writing skills were predicted by early competences, albeit with differences across countries.

Conclusions Findings suggest that literacy acquisition trajectories are not only associated with early skills but are also influenced by language characteristics and curriculum practices. The study also presents preliminary findings relative to the 'Talk', an assessment tool that may have important implications for early identification and intervention of language and literacy difficulties, as well as for improving cross-country curriculum practices.
\end{abstract}

Keywords Language $\cdot$ Literacy · Orthographic consistency · Preschool curriculum • Primary school

Tamara Bastianello

tamara.bastianello@univr.it

Extended author information available on the last page of the article 


\section{Introduction}

Studies have shown that the possession of the skills that are at the basis of literacy acquisition at preschool is associated with more successful reading and writing acquisition processes at primary school. The children who already master these basic (or early literacy) skills at the start of primary school learn to read and write more quickly and are thus better equipped for academic success (Catts et al., 1999; Dickinson et al., 2010; Kendeou et al., 2009; National Early Literacy Panel-NELP, 2008; National Institute of Child Health and Human Development Early Child Care Research Network-NICHD-ECCRN, 2005). Early literacy acquisition entails the development of the ability to discriminate, encode, and manipulate the language sound structures (i.e., phonological awareness; Bar-Kochav \& Nevo, 2019; Daffern, 2018; Goswami, 2014; Lervåg et al., 2009; Pennington et al., 2001; see Melby-Lervåg et al., 2012, for a review); the ability to store them in memory (i.e., phonological memory; Gray et al., 2019); the ability to manipulate and combine meaningful language units (i.e., morpho-syntax; Snowling et al., 2003); the ability to quickly retrieve and produce words (measured using Rapid Automatic Naming tasks, hereafter RAN; see Araújo et al., 2015, for a meta-analysis; see Kirby et al., 2010, and Norton \& Wolf, 2012, for a review); the ability to produce language and express ideas (Cain \& Oakhill, 2011; Quinn et al., 2015; Sénéchal et al., 2006); and the ability to coordinate visual and motor processes (or visual-motor coordination; Dinehart, 2015; Zemlock, Binci-Booher, \& James, 2018). Adequately assessing these skills at an early stage of the child's life is important, as a delay in their development may be an early sign of a language delay or a reading disorder. To maximize identification chances, ideal early literacy skill tests should be quite short and usable by teachers and educators. While several tasks have been created to investigate one or more of these early literacy skills, to the best of our knowledge, a unique and multidimensional tool to gain a comprehensive measure of the children's early literacy skills at preschool has never been designed. Yet, developing a tool that estimates the level of the children's early literacy development and that could be used by teachers would be important, not only for the early identification of possible reading or language disorders (Wilcox et al., 2020; Wilcox et al., 2011; Catts et al., 1999; Kendeou et al., 2009; McIlraith \& LARRC, 2018), but also to design early intervention programs and facilitate the children's transition to primary school (Justice et al., 2002).

Ideally, such a tool should also be appliable to different countries and contexts. However, the predictiveness of the children's early literacy skills for their later reading and writing acquisition processes is likely to differ between countries, as a result of intervening contextual factors. One of the factors that is thought to affect literacy acquisition trajectories across languages is the level of orthographic consistency (transparency, regularity, and consistency) of the language spoken/used at school (Landerl et al., 2019; Ziegler \& Goswami, 2005; Ziegler et al., 2010; see Tiron \& Gherguț, 2019, for a review). Previous studies comparing reading acquisition across languages have shown that more transparent systems (i.e., systems that have more consistent sound-to-letter correspondences) are associated with easier and quicker literacy acquisition processes (Aro \& Wimmer, 2003; Caravolas et al., 2013; Patel et al., 2004; Seymour et al., 2003). In a longitudinal study on school-aged children, Caravolas and colleagues (2013) have shown that reading acquisition proceeds at different speed in languages with different degrees of orthographic consistency: reading skills progress more slowly for children acquiring English than for children acquiring languages with more regular orthographies such as Spanish and Czech. The higher difficulty in learning to read in more opaque orthographies also leads to lower reading accuracy 
at primary school: as shown by Seymour et al. (2003), primary school children acquiring English, Danish, or French make, on average, significantly more mistakes than children acquiring languages with transparent orthographies (e.g., Finnish, Greek, or Italian). It has been hypothesized that reading in opaque vs. transparent orthographies follows different trajectories, because it is inherently based on different processes and because it requires the development of different early literacy skills. In line with this idea, studies have shown that the efficiency of phonological awareness and RAN tasks in predicting dyslexia varies across languages with different degrees of orthographic consistency: performance in RAN tasks is more predictive than performance in phonological awareness in transparent orthographies (Jong \& van der Leij, 2003; Wimmer et al., 2000), while the opposite is true for opaque orthographic languages (Caravolas, Volin, \& Hulme, 2005; Patel et al., 2004; see Tiron \& Ghergut, 2019, for a review).

As shown by Inoue et al. (2020), other factors besides orthographic consistency may intervene: in their study the differences between the reading abilities of school-age children speaking English, Dutch, German, or Greek were more affected by variables such as the educational context in which the children lived than by the language's orthographic consistency. The early learning experiences and the kind of activities that are carried out at preschool seem to have a significant impact on the acquisition and development of literacy skills (Campbell et al., 2001; Graue, Clements, Reynolds, \& Niles, 2004; Nelson, Brenner, \& Gonzalez, 2003). Structured activities focused on teaching preschoolers letter naming/ writing and word rhyming do enhance alphabet and letter word recognition, while meaning-focused activities (such as reading a book to children) stimulate vocabulary growth (Connor et al., 2006); the teachers' level of responsiveness to the academic activities also predicts the children's early reading skills (Connor et al., 2005). Thus, the decision to focus preschool curricula on one activity rather than on another is likely to have an effect on the development of the children's reading skills. Orthographic consistency and preschool activities could also influence the relationship between the children's early literacy skills and their later reading and writing performance. If that were the case, the relationship between early and later literacy skills would differ across countries and contexts.

\section{Purpose and Research Questions}

The present study is part of a broader project focused on the transition from preschool to primary school across different European countries. The project 'Teaching and Assessing Language for Kids' (hereafter 'Talk') combines a range of methodologies in a crosscultural/linguistic perspective and has the aim to (i) implement an original and multidimensional assessment that could be used by preschool teachers to enhance and support the transition of preschool children to the first year of primary school in different countries, and (ii) to identify the key predictors of later reading and writing performance at primary school. The children's early literacy skills (phonological awareness, vocabulary, and morphosyntax) were tested using a multidimensional evaluation tool based on Information and Communication Technologies created ad-hoc for the present project: Talk. RAN and visual-motor coordination were also evaluated at preschool.

To explore the roles of orthographic consistency and of preschool curriculum in shaping the children's literacy acquisition processes, for the present study we tested children from three different countries: Italy, Romania, and Belgium. Italian, Romanian and Flemish are all Indo-European languages; however, they have different roots. In fact, while Italian and Romanian are closely related Romance languages, Flemish is a Lower Franconian/Dutch 
dialect. Italian and Romanian have a transparent orthographic system, while Flemish has an opaque orthographic system, which means that the relationship between sounds and letters in Italian and Romanian is more predictable than it is in non-transparent orthographic systems such as that of Flemish. On the other hand, Italy and Belgium differ from Romania in their preschool curricula: Italy and Belgium follow more traditional approaches within their classrooms (i.e., without any specific intervention on a single language domain), whereas in Romania preschool activities are designed to facilitate the development of the prerequisites for the reading and writing processes and are especially focused on the development of oral language and lexical skills. Based on these orthographic system and preschool curriculum differences, we expect:

(1) overall performance in early literacy skills (phonological awareness, lexical, and morphosyntactic skills) and in RAN to be highest in Romania (transparent orthographic system; vocabulary-based curriculum) and higher in Italy (transparent orthographic system; traditional curriculum) than in Belgium (opaque orthographic system; traditional curriculum). Performance in the grapho-motor task is not expected to differ between countries, as visual-motor coordination skills should be independent of the orthographic consistency and preschool curriculum effects.

(2) the scores obtained by the children in the Talk assessment, the RAN, and the graphomotor task at preschool to predict their reading and writing performance at the end of first grade, albeit with differences across countries. Performance in the grapho-motor task (which assumes good visual-motor coordination) at preschool should be predictive of writing performance at primary school in all countries; on the contrary, as a result of orthographic system differences, we expect the Talk assessment and the RAN task to explain more variance in the Italian and Romanian children's reading and writing scores than in those of the Belgian children.

\section{Method}

\section{Design}

The longitudinal research was conducted transnationally over two years. The children were tested twice: the first time at the end of their last academic year of preschool (June/July 2018), the second time towards the end of the first year of primary school (i.e., first grade; Belgium and Italy) or towards the end of the preparatory class (Romania) (April 2019, follow-up). At the first assessment children were administered the Talk assessment, created ad hoc for the present project, and a receptive vocabulary test. At the second assessment the children's reading and writing skills were evaluated. All the countries followed the same research design.

\section{Participants}

A total of 363 children aged five years had initially been recruited for the present project. However, 116 of these had to be excluded for one or more of the following reasons: (i) because they were unable to complete all tests due to their inability to stay focused on the task or because they found the task too difficult, or (ii) because they were not at school the day of at least one of the assessments. The final participant sample at preschool was 
constituted by 247 children: 73 from five schools in Italy, 65 from two schools in Romania, and 109 from three schools in Belgium. At the time of the first assessment (at the end of the last year of preschool), the Belgian children (55 boys) had a mean age of 66.82 months $(S D=3.62)$, the Italian children (31 boys) of 65.71 months $(S D=3.79)$ and the Romanian children ( 42 boys) of 67.6 months $(S D=3.01)$. From the initial sample of 247 children, 45 more dropped out before they could be tested again at primary school for one of the reasons mentioned above or because their parents did not re-new their consent for the second data collection session. This caused the Italian sample to be left with 39 children and that in Belgium with 98 children at the time of the second assessment. The mothers and fathers of the children in the final sample $(n=202)$ had studied for an average of $13.08(S D=3.09)$ and $12.11(S D=3.83)$ years, respectively.

The families who decided to participate in the present study had participated in a preliminary meeting organized to present and explain the project to the children's teachers and parents and had signed an informed consent form before the data collection started. The research protocol was approved by the local ethical committee before the start of the study. Each country prepared their own informed consent following the legal guidelines of their country. The authors declare they have no conflict of interest.

\section{Instruments}

The characteristics of the tasks used to assess the children's early literacy skills and their reading and writing abilities are summarized in Table 1 . Three standardized tests were used to test the validity of the Talk assessment in measuring the children's lexical abilities: the Italian and Flemish versions of the Peabody Picture Vocabulary Test for Italian and Belgian children and the Denver Developmental Screening Test for Romanian children. The sections below describe first the tests used to assess the validity of the Talk and then the tests used to measure the children's early literacy and reading and writing skills.

\section{Peabody Picture Vocabulary Test for Italian and Belgian Children}

The Peabody Picture Vocabulary Test-PPVT (Dunn \& Dunn, 1981) is a standardized test of receptive vocabulary size. The Italian version of the PPVT (Stella, Pizzioli, \& Tressoldi, 2000) is designed for children between 3.9 and 11.6 years of age; the Flemish version (Schlichting, 2005) is designed for children and adults between 2.3 and 90 years. All versions have a total of 175 items, with 5 familiarizations tests. The PPVT consists in a four-choice task in which the child is required to tell or point to the figure corresponding to the target word spoken by the experimenter. The final score is tallied from the difference between the floor and ceiling scores. The final score was then adjusted for the child's chronological age. The reliability of the original version of the PPVT is between 0.61 and 0.88 for children.

\section{Denver Developmental Screening Test (DDST II) for the Romanian Group}

Because the Romanian version of the PPVT does not exist, the Romanian children's vocabulary skills were measured using the Denver Developmental Screening Test (DDST II; Frankenburg \& Dodds, 2010), which is designed to identify developmental disorders in children aged between 0 and 6 years. It comprises 125 items focusing on i) personal-social 


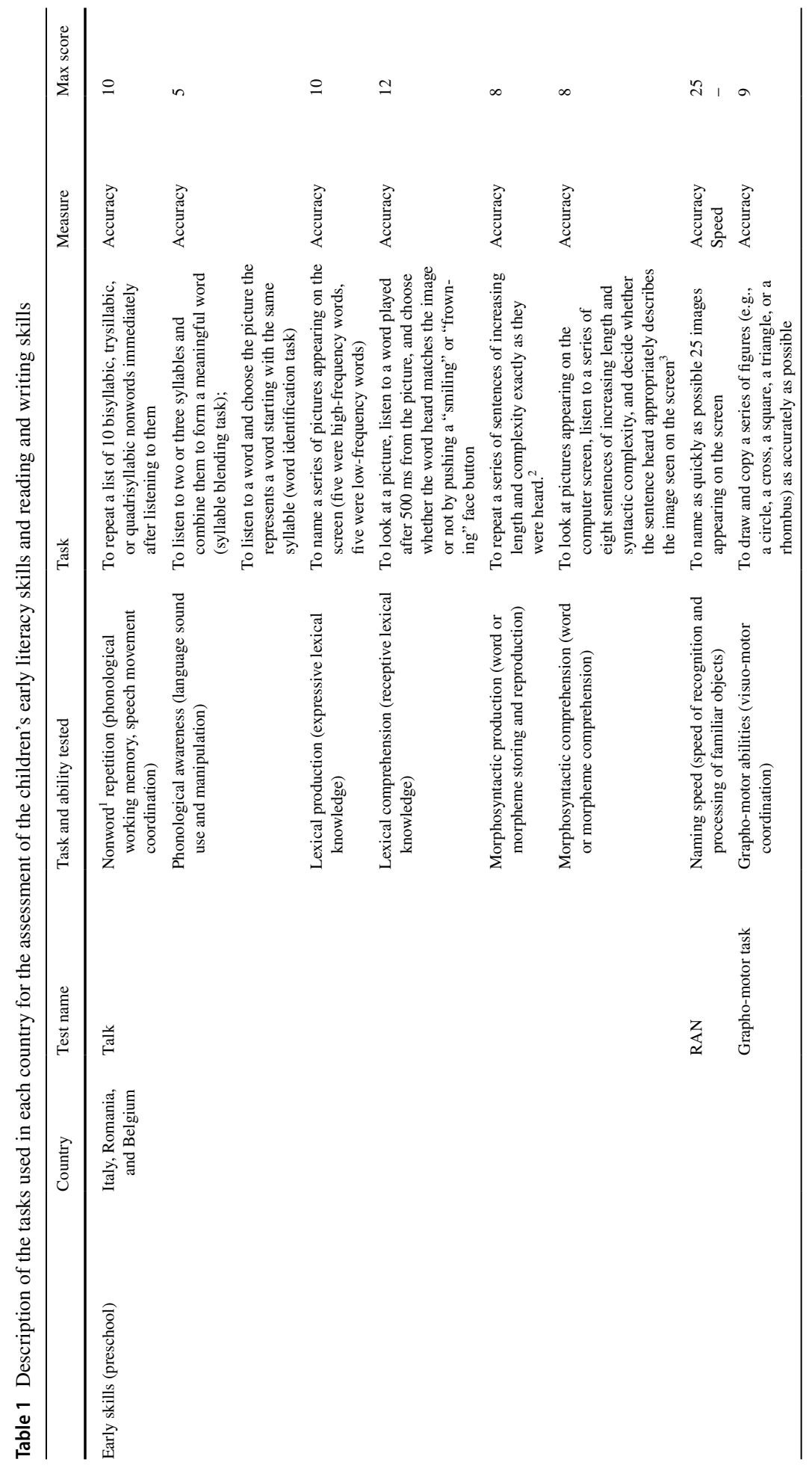




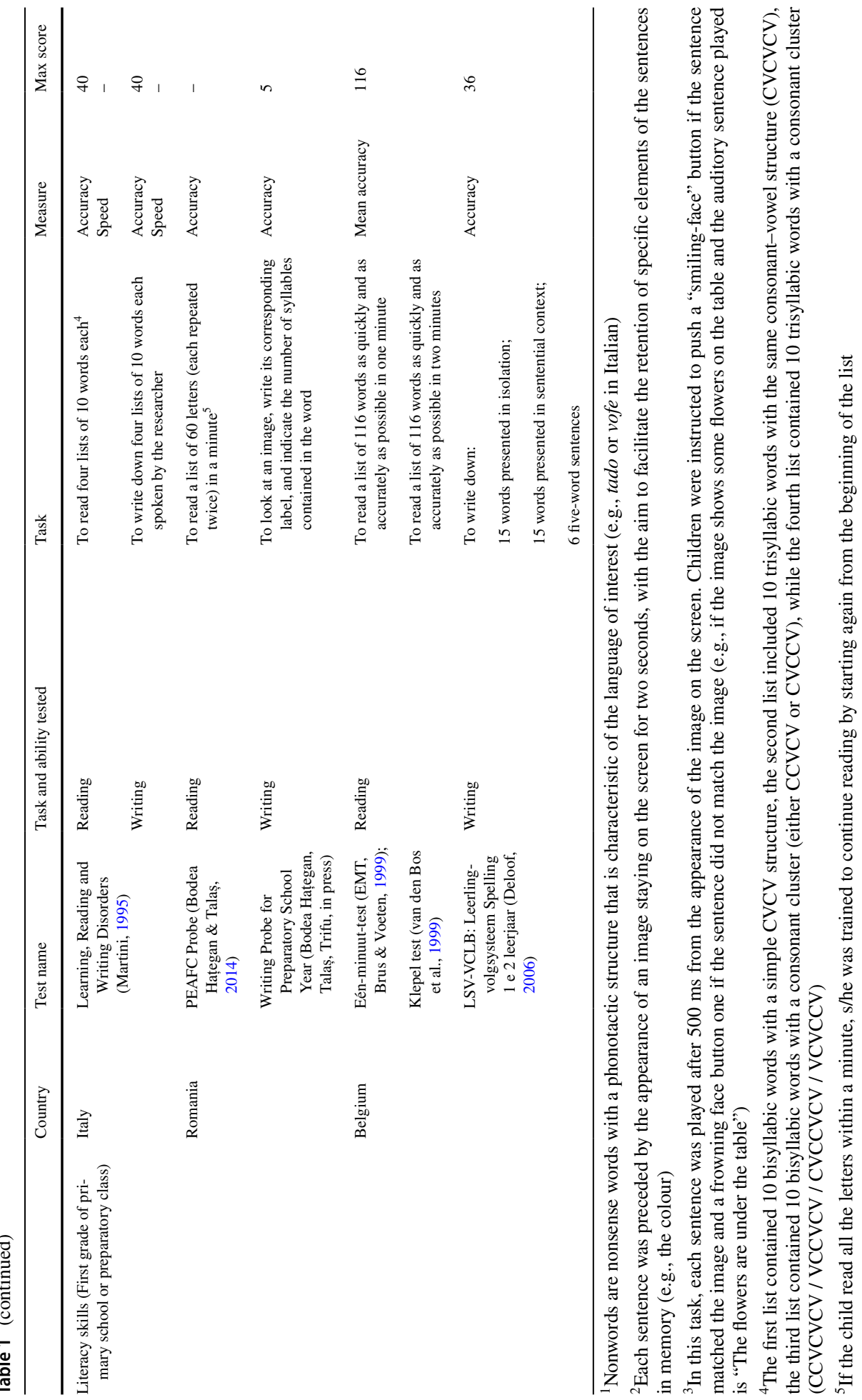


abilities (25 items), ii) fine motor/adaptative skills (29 items), iii) language (39 items) and iv) gross motor skills (32 items). The translation and standardization of the DDST II for Romania were performed by Iliescu and Mitrofan between 2009 and 2010, based on a sample of 1391 children. For the purpose of the present study only the language scale was administered. The final raw score was adjusted for linguistic age.

\section{Early Literacy Skills at Preschool}

\section{The Talk Assessment}

The Talk assessment is a multi-dimensional assessment tool that was built ad hoc for the present project. The aim was to create a tool that would be usable by teachers in multiple countries to measure the children's early literacy skills before the transition to primary school and to identify possible fragilities that may lead to later literacy difficulties. The instrument was constructed to be used on devices such as tablets or computers and functions as a game guided by a character, Arturo the kangaroo, who helps the child through the activities. Based on the literature, six dimensions corresponding to different language domains were included in the Talk final version: nonword repetition, phonological awareness, lexical production, lexical comprehension, morphosyntactic production, and morphosyntactic comprehension. The participant's answer is categorized as correct or incorrect by the researcher administrating the task; the system automatically records the response time. At the end of each game, the data recorded are automatically saved in an individual file that contains the descriptive scores (accuracy and time). Three versions of the Talk were constructed and adapted to the linguistic characteristics of each group. Each child received the Talk assessment in the main language spoken at preschool (Italian, Romanian or Flemish Dutch).

\section{Rapid Automatized Naming (RAN)}

This computerized test was used to measure the children's ability to recognize and process familiar objects (Brizzolara et al., 2006) and to retrieve words for them. Each child was presented with 25 highly familiar visual stimuli/objects (e.g., mouse, apple, boat, foot, and moon) appearing on a computer screen. The person administering the test indicated whether the children had named the picture correctly; naming time was automatically calculated. See Table 1 for more details.

\section{Grapho-motor Task}

To measure the children's visual-manual abilities, a grapho-motor task was created and administered. Children were presented with a paper sheet with three columns (two of which were empty) and five rows containing the ideal figures that the child was expected to copy (i.e., a circle, a cross, a square, a triangle, or a rhombus). Each child had two attempts for each figure. The criteria of similarity (i.e., how similar the child's attempt was to the target figure) was used to score the task in all the three countries by using a $0-2$ points scale $(0=$ the figure was not drawn or is completely different from the target figure; $1=$ the figure is non-regular but presents well-aligned lines; $2=$ the figure is regular and very similar to the target figure, the lines touch together). The final accuracy score was given by the mean accuracy of the two attempts. See Table 1 for more details. 


\section{Literacy Outcomes at the End of First Grade}

The children's reading and writing skills were tested at the end of the first year of primary school, nine months after the first assessment. Each country used different tests to evaluate the children's performance in reading and writing. See Table 1 for details on the tasks in each country.

\section{Italy}

The Italian group used the Martini's reading and writing test (Martini, 1995). Each child was asked to read and write four lists of 10 words each, for a total of 40 words. In the writing test, the experimenter read aloud a word and the child had to write it down. The child was encouraged to read and write as well as possible. The number of orthographic errors was used as a measure of accuracy.

\section{Romania}

The Romanian children's reading skills at the end of the preparatory class were assessed using the PEAFC Probe (Probe for Assessing and Training Reading Fluency in Romanian language; Bodea Hațegan, \& Talaş, 2014), which has a Cronbach's alpha reliability coefficient of 0.93 . The children's writing skills were assessed using the Writing Probe for Preparatory School Year (Bodea Hațegan, Talaș, \& Trifu, in press). The Cronbach's alpha of the original version of this test is of 0.75 .

\section{Belgium}

The reading skills of the Belgian children were tested using the Eén-minuut-test A \& B test (EMT; Brus \& Voeten, 1999, which has a (Pearson's) reliability coefficient between 0.89 and 0.95) and the De Klepel Pseudowoordentest Vorm A en B test (Klepel test; van den Bos et al., 1999). To test the children's writing skills, three tasks of the LVS-VCLB test were used (Deloof, 2006). For the purpose of the present study, two single standard scores were extracted from the tests: the "Total reading score" and the "Total writing score".

\section{Procedure}

Several local schools in each country of interest were contacted to participate in the project. These schools were assumed to represent the typical environment in which the children of that country are raised and develop their basic competences for the transition to primary school. A few schools were already involved in language-oriented projects and decided not to participate. Three schools from Flanders in Belgium, five from two north regions of Italy, and two from the north-western part of Romania agreed to participate. The number of participating schools in each country depended on the total number of children recruited, which had to be at least 100 per country.

Two meetings, one with teachers and one with parents, were organized and held in each school by the researchers involved in the project to present and explain the study. All the researchers involved in the project had been instructed and trained in the same way, so as to 
evaluate the children in a correct and systematic way and to make cross-country comparisons possible. All the tasks to be administered were also jointly shared between the authors of the project prior to the start of the study.

All children were tested in two sessions. The first assessment (in preschool) involved the use of four tests: a standardized vocabulary test (the PPVT or the Denver test), the Talk assessment, the RAN task, and a grapho-motor task. The second assessment (at the end of first grade, nine months after the first assessment) included reading and writing tests and a second assessment of the children's receptive vocabulary skills. Each assessment was conducted by a trained researcher in a silent room during school hours and took approximately 30 min in total. After the end of the assessment, each child was accompanied back to his/ her classroom. As explained in the Participants section, a few of the children tested at preschool in Italy and Belgium $(n=45)$ could not be tested again at end of first grade. All the authors take responsibility for the integrity of the data and the accuracy of the quantitative data analysis.

\section{Data Analysis}

Validity and reliability measures for the Talk assessment in the three countries were calculated using correlation tests between the Talk total score and the score obtained in the standardized vocabulary test, and by calculating McDonald's omega $(\omega)$, respectively. Due to the fact that most of the data did not meet parametric assumptions, correlations were run using Kendall's tau-b tests.

To investigate whether children's early literacy skills were affected by orthographic consistency and preschool curriculum, we compared the mean scores obtained by each child in the Talk assessment (both in each subtest and overall), in the RAN, and in the grapho-motor tasks at the end of the last year of preschool between countries. Because Shapiro-Wilk tests showed that the distribution of the scores within each country was nonnormal (all $p \mathrm{~s}>0.05$ ), between-country comparisons were carried out using a series of Kruskal-Wallis tests. In all cases, post-hoc tests were conducted using pairwise Wilcoxon tests with the Bonferroni correction.

The relationship between our early literacy measures at preschool and the children's reading and writing outcomes at the end of first grade in each of the three countries was assessed using Kendall's tau-b correlation tests and multiple linear regressions. The children's reading and writing outcomes were evaluated separately for each country and not compared between countries, because they were measured using different tasks with different scales. All statistics were conducted using JASP (JASP Team, 2019).

\section{Results}

\section{Validity and Reliability of the Talk Assessment}

Correlation tests showed that the scores obtained by the children in the Talk subtest focused on receptive vocabulary (lexical comprehension) were positively and significantly correlated with the performance shown in the standardized vocabulary test PPVT (Italy: Kendall's tau $(\tau)=0.304, p<0.001$; Belgium: $\tau=0.491, p<0.001$ ), thus suggesting good test validity as regards lexical comprehension. Because the standardized test used for Romania (i.e., Denver) measured skills in several language domains, in the case of the Romanian 
children we expected to find significant correlations between the Talk total score and the overall language score achieved in the Denver test; however, statistical tests showed that this was not the case $p>0.05$ ). We can partially confirm that the results obtained in the Talk assessment are in line with the results obtained by the same children through a standardized assessment tool.

The McDonald's $(\omega)$ value was checked for the normalized distribution (z-scores) of the scores obtained in each task of the Talk assessment to test the reliability of this new assessment tool in each country. The McDonald's value was 0.749 (item reliability min-max: 0.668-0.742) for the Italian group, 0.716 (item reliability min-max: 0.593-0.767) for the Belgian group, and 0.756 (item reliability min-max: 0.689-0.768) for the Romanian group. The internal consistency of the tool can be considered sufficiently good in all countries (coefficients should be at least between 0.50 and 0.75; Reise, 2012; Reise et al., 2013).

\section{Early Literacy Skills at Preschool Across cCountries: the Effect of Orthographic Consistency and Preschool Curriculum}

Table 2 displays the mean scores obtained by the children in the Talk assessment (both in total and in each subtest), in the RAN task (accuracy and speed), and in the graphomotor task. Mean accuracy scores in each task and in each country were medium-high with respect to the maximum score that could be obtained (see Table 1). A series of Kruskal-Wallis test showed that the performance in early literacy skills differed significantly between countries (see Table 2).

More specifically, in line with our hypothesis that early literacy skills would be influenced by language orthographic consistency, we found that the Belgian children scored lower than one or both of the other two groups on several of the Talk subtests. Post-hoc tests showed lower scores in Belgium than in Romania as regards phonological awareness, lexical production, and morphosyntactic production and comprehension; they also showed lower scores in Belgium than in both Romania and Italy in the tasks investigating nonword repetition, lexical comprehension, and RAN.

In line with our hypothesis that preschool curricula would also have an effect on the children's early literacy skills, post-hoc tests also showed that the children in Romania scored higher than those in Italy in lexical production and in the Talk assessment overall, despite speaking languages with a comparable degree of orthographic transparency. Moreover, the performance of the children in Italy was comparable to that of the children in Belgium in phonological awareness, lexical production, morphosyntactic production, and morphosyntactic comprehension, which suggests that variance in early literacy skills does not depend only on orthographic transparency.

Interestingly, the total score obtained in the Talk assessment appeared to reflect the differences between countries in relation to both factors: post-hoc tests showed significantly lower scores in Belgium than in the countries with higher orthographic consistency (i.e., Italy and Romania), and significantly lower scores in Italy than in the country employing a preschool curriculum focused on enhancing early literacy skills (i.e., Romania; see Table 2 for details). This suggests that the total Talk score adequately reflects group differences due to orthographic consistency and preschool curriculum (see Fig. 1).

Between-country differences were also found in the $R A N$ task. The children speaking languages with similar orthographic consistency (i.e., Italian and Romanian) showed similar performance in this task, both in terms of accuracy and speed, and were significantly faster than the children in Belgium (see Table 2). The Belgian 


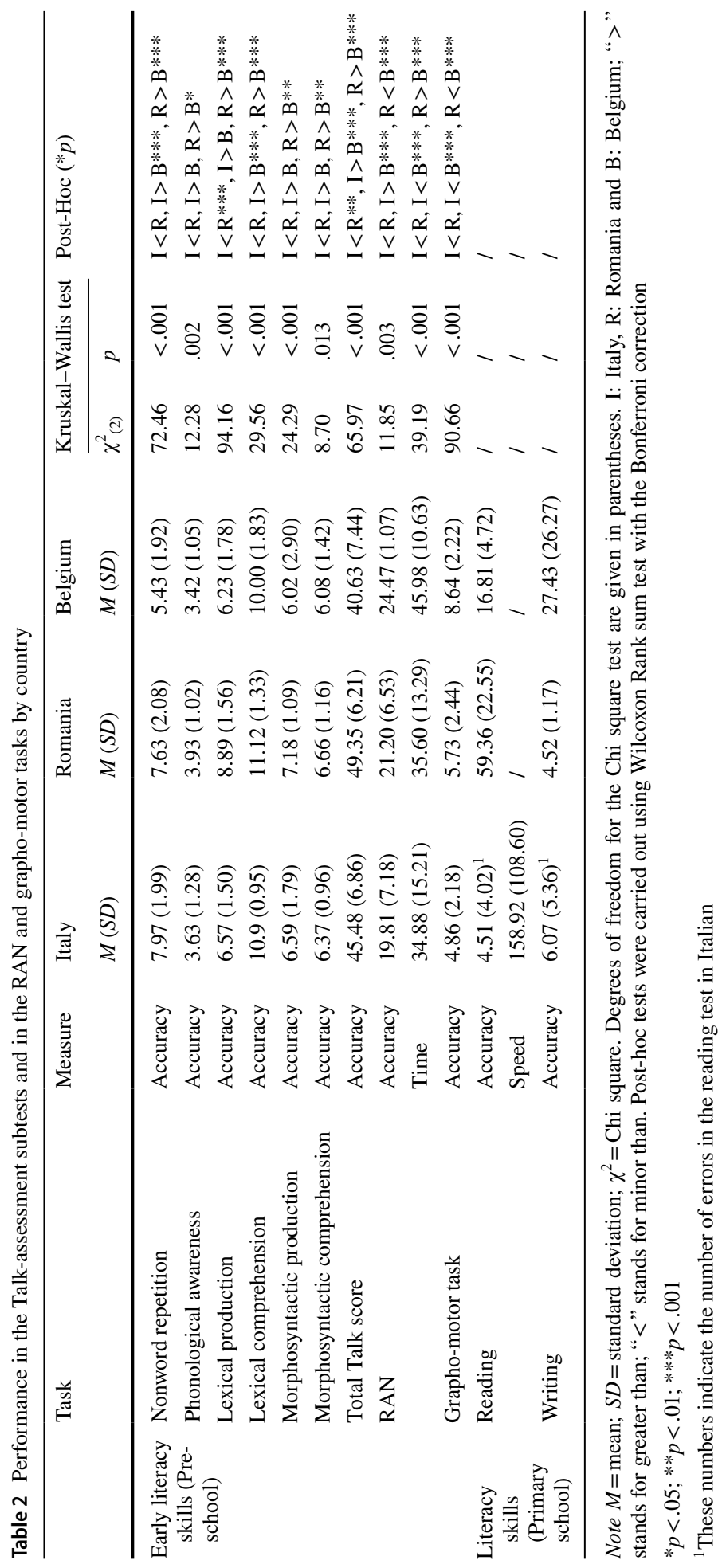




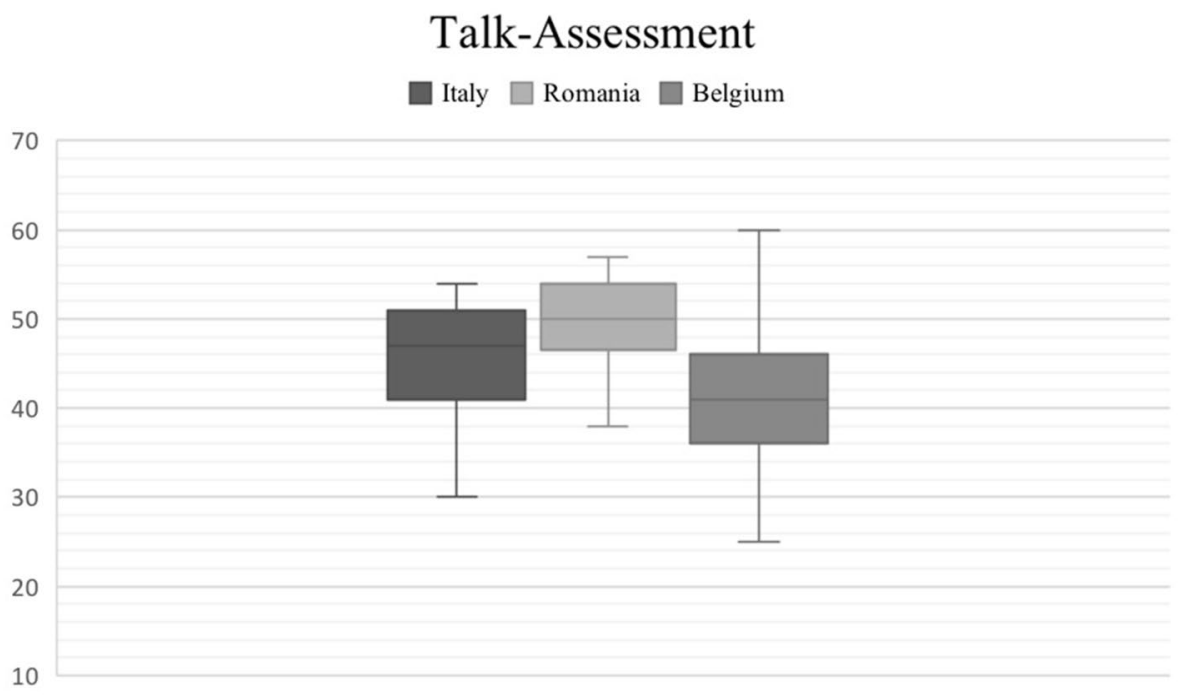

Fig. 1. Total scores in the Talk-assessment by country

children showed significantly higher naming accuracy as compared to the Italian and Romanian children; however, their significantly slower speed suggests that these better results may be due to the longer time they took to complete the task (see Table 2). The lack of naming accuracy differences between Italy and Romania suggests that performance in this task may not be heavily affected by the preschool activities in which the children participate, but may be more dependent on the maturation of skills such as the ability to recognize and process familiar objects and the ability to quickly retrieve and produce words.

In contrast with our hypotheses regarding the absence of differences between countries in the grapho-motor task, pairwise Wilcoxon tests showed that the children in Belgium achieved significantly higher scores as compared to the children in both Italy and Romania (see Table 2).

\section{The Relationship Between Early Literacy Skills and Reading and Writing Performance at Primary School: Are Early Literacy Skills Successful at Predicting Later Reading and Writing Performance Across Countries?}

Table 2 shows the mean scores obtained by the children in the reading and writing tests at the end of first grade in the three countries. Note that different reading and writing tests were used across countries; therefore, the reading and writing abilities of the children in each country were evaluated separately. All participants scored within the normative range of each country. The sections below describe the results of the tests used to investigate (i) whether early literacy skills (measured using the Talk, RAN, and grapho-motor tasks) at preschool correlate with reading and writing abilities at primary school, and (ii) whether early literacy skills explain variance in the children's reading and writing scores at primary school. 


\section{Correlations}

The results of the Kendall tau-b correlation tests investigating the relationship between the children's early literacy skills at preschool and their reading and writing performance at primary school are reported separately for each country below and in Table 3.

\section{Italy}

For the Italian group, tests showed significant, negative, and moderate correlations between the total score obtained in the Talk assessment at preschool and the errors shown in the writing test at primary school. Tests also showed significant, negative, and moderate correlations between the children's RAN accuracy at preschool and their reading times a primary school, as well as between their accuracy in the grapho-motor task at preschool and their reading errors at primary school (see Table 3). In sum, the children who had better naming scores at preschool showed faster reading times at the end of first grade; the children who had better grapho-motor and total Talk scores at preschool showed better writing accuracy at the end of first grade.

Table 3 Kendall's tau-b coefficients and their significance for the correlation tests between the children's early literacy scores (as measured by the Talk assessment and by the RAN and grapho-motor tasks) and their reading and writing scores in each country

\begin{tabular}{|c|c|c|c|c|c|c|c|}
\hline & 1 & 2 & 3 & 4 & 5 & 6 & 7 \\
\hline \multicolumn{8}{|l|}{ Italy } \\
\hline 1. Total Talk score & - & & & & & & \\
\hline 2. RAN accuracy & -0.146 & - & & & & & \\
\hline 3. RAN time & $-0.354 * * *$ & $0.395^{* * *}$ & - & & & & \\
\hline 4. Grapho-motor accuracy & 0.103 & $0.283^{* *}$ & 0.119 & - & & & \\
\hline 5. Reading accuracy (errors) & -0.12 & $-0.329 *$ & 0.079 & -0.217 & - & & \\
\hline 6. Reading time & -0.089 & -0.233 & 0.015 & $-0.24 *$ & $0.471 * * *$ & - & \\
\hline 7. Writing accuracy (errors) & $-0.239 *$ & -0.013 & -0.052 & -0.16 & $0.319 * *$ & $0.297 *$ & - \\
\hline \multicolumn{8}{|l|}{ Romania } \\
\hline 1. Total Talk score & - & & & & & & \\
\hline 2. RAN accuracy & $0.265^{* *}$ & - & & & & & \\
\hline 3. RAN time & -0.007 & $0.416^{* * *}$ & - & & & & \\
\hline 4. Grapho-motor accuracy & $0.192 *$ & $0.291 * *$ & 0.034 & - & & & \\
\hline 5. Reading fluency & 0.169 & 0.134 & -0.064 & 0.053 & - & & \\
\hline 6. Write and indicate syllables & -0.078 & -0.255 & -0.065 & 0.035 & 0.131 & - & \\
\hline \multicolumn{8}{|l|}{ Belgium } \\
\hline 1. Total Talk score & - & & & & & & \\
\hline 2. RAN accuracy & 0.123 & - & & & & & \\
\hline 3. RAN time & $-0.169 *$ & 0.065 & - & & & & \\
\hline 4. Grapho-motor accuracy & 0.050 & 0.009 & $-0.142 *$ & - & & & \\
\hline $\begin{array}{l}\text { 5. Reading accuracy (correct } \\
\text { items) }\end{array}$ & -0.004 & -0.017 & $-0.244 * * *$ & $0.165^{*}$ & - & & \\
\hline $\begin{array}{l}\text { 6. Writing accuracy (correct } \\
\text { items) }\end{array}$ & $0.179^{*}$ & 0.036 & $-0.273 * * *$ & $0.185^{*}$ & $0.443 * * *$ & & \\
\hline
\end{tabular}

$* p<.05, * * p<.01, * * * p<.001$ 


\section{Romania}

No correlations were found between the Romanian children's early literacy scores at preschool and their reading and writing performance nine months later (see Table 3).

\section{Belgium}

Tests showed significant and positive correlations between the total Talk score and the Belgian children's writing accuracy, which means that the children who had better scores in the Talk at preschool showed better writing performance at the end of first grade (see Table 3). Tests also showed significant and negative correlations between the children's RAN times at preschool and the number of words correctly read and written at primary school (see Table 3), thus meaning that the children who had faster naming times also showed better reading and writing skills at primary school nine months later. Significant, positive correlations were also found between accuracy in the grapho-motor task at preschool and reading and writing accuracy at primary school (see Table 3).

\section{Multiple Linear Regressions}

Multiple linear regressions tested whether early literacy skills at preschool were significant predictors of the children's reading and writing outcomes at the end of first grade. The results of these regressions are reported in Table 4 and described below, separately for each country. Collinearity statistics, Tolerance, and VIF were checked: no assumptions were violated.

\section{Italy}

As reported in Table 4, the only model that significantly predicted the children's scores was that on writing errors $(F(3,34)=3.285, p=0.032)$; as shown by the adjusted $\mathrm{R}^{2}$ value, this model explained $15.6 \%$ of the variance in the children's writing data (see Table 4$)$. In this case, the only significant predictor was the total Talk score $(p=0.030)$; as shown by the standardized beta coefficients reported in Table 4, the total Talk score achieved at preschool was negatively related to the number of writing errors made at the end of first grade. In other words, the children who performed better in the Talk assessment at preschool showed better writing performance later at primary school. The same model on reading errors only approached significance $(F(3,34)=2.569, p=0.070)$. None of our early measures were predictive of reading times (see Table 4 ).

\section{Romania}

Tests showed that only the model on reading fluency was significant $(F(3,60)=3.260$, $p=0.028$; see Table 4). This model predicted $9.7 \%$ of the variance in the children's reading fluency; however, none of the early literacy scores was a significant predictor. These results suggest that early literacy skills may predict later reading performance, but only if the participants' scores in the Talk, RAN, and grapho-motor tasks are all entered in the model together. 


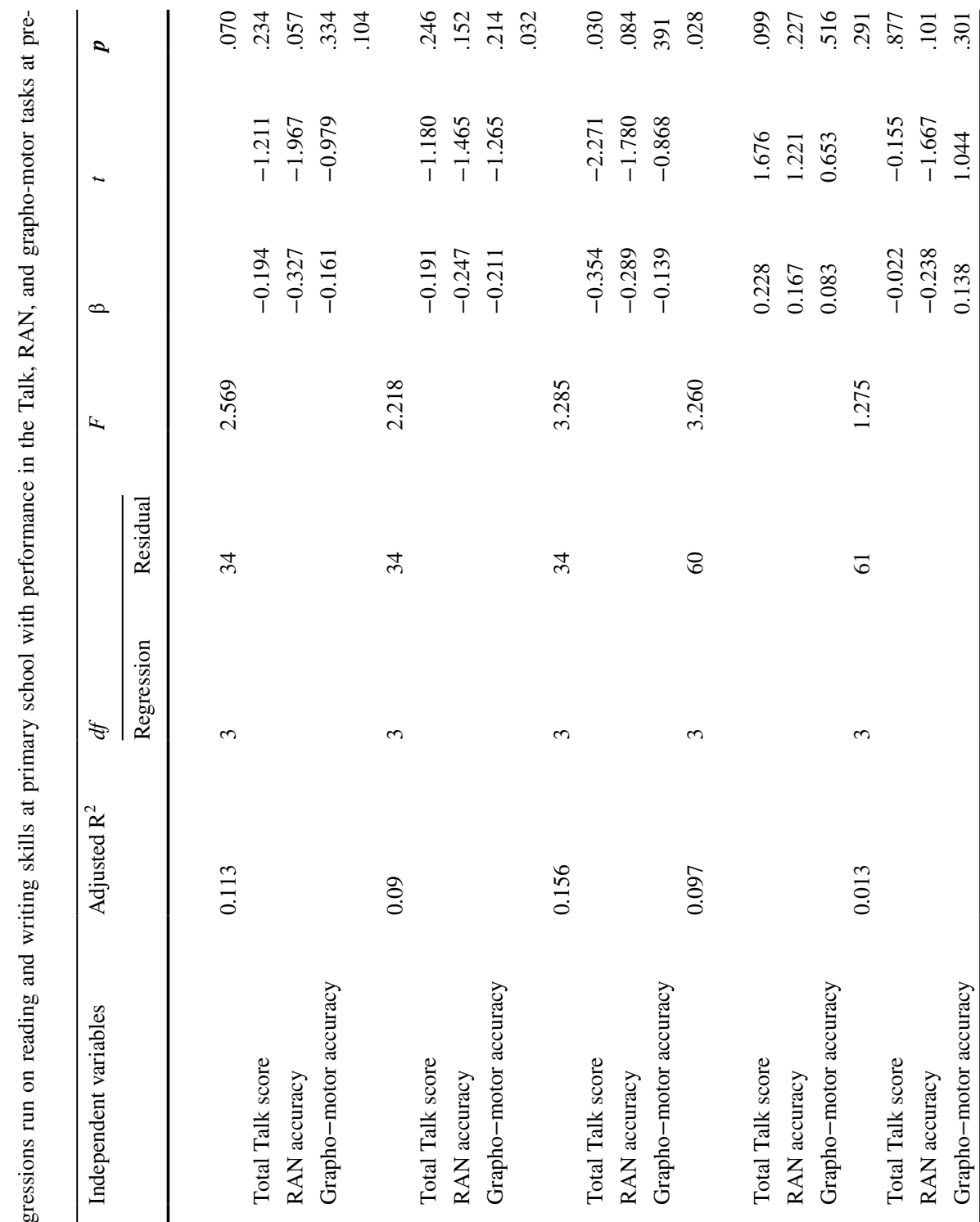




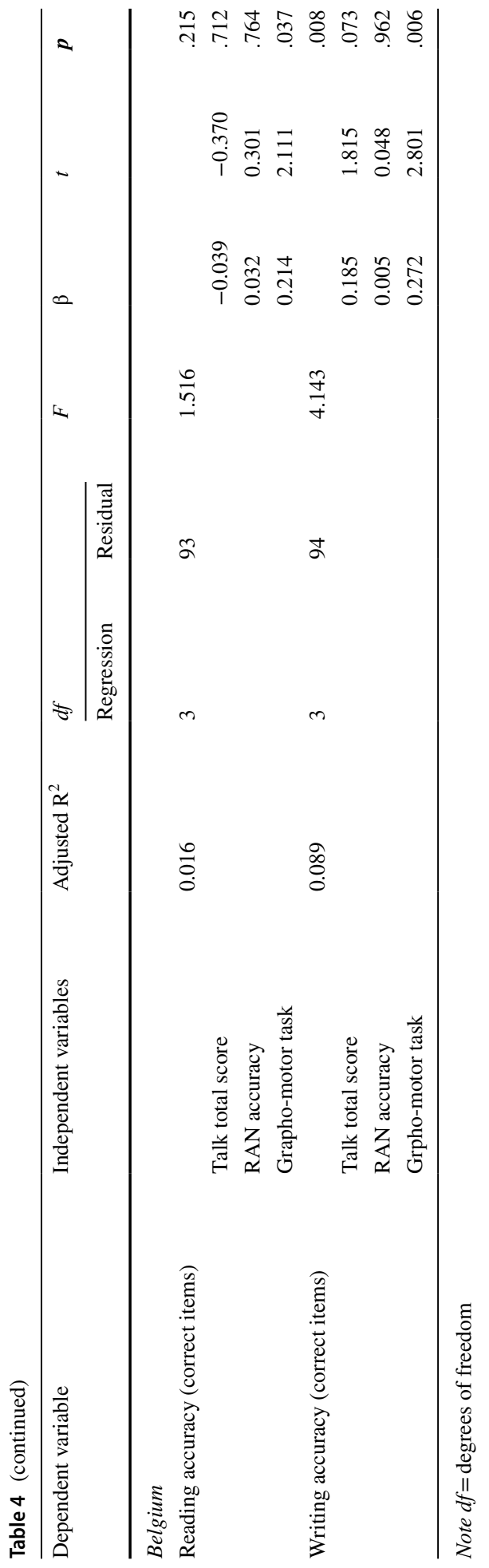




\section{Belgium}

Tests showed that only the model on writing accuracy was significant $(F(3,94)=4.143$, $p=0.008)$. Here, the most important predictor was the grapho-motor task: although both the total Talk score and the grapho-motor task score were significant predictors of the children's writing performance, the latter showed a higher beta coefficient, suggesting higher influence on the dependent variable (see Table 4). The model on writing accuracy explains, overall, $8.9 \%$ of the variance in the children's writing scores (see Table 4). The graphomotor task was also the only significant predictor in the model on the children's reading accuracy at primary school ( $p=0.037$; see Table 4$)$.

\section{Discussion}

The first aim of the present study was to assess whether variability in the skills that are at the basis of literacy acquisition (as measured using the Talk, RAN, and grapho-motor tasks) across countries is influenced by the orthographic transparency of the language spoken and/ or by the curriculum activities carried out at preschool. To investigate the role of orthographic transparency, we compared the performance of children acquiring Italian or Romanian to that of children acquiring Flemish, a language with a more opaque orthographic system. We hypothesized that Italian and Romanian children would score better than Flemish children in the Talk assessment and in the RAN task (due to their language orthography being more transparent) and that all children would score similarly in the grapho-motor task (as performance in this task should be independent of language effects). In line with this idea, results showed the performance of the Belgian children in phonological awareness, lexical production, and in morphosyntactic production and comprehension was significantly lower than that of the Romanian children; their performance in the tasks investigating nonword repetition, lexical comprehension, and in total in the Talk assessment were also significantly lower than those of the children from both Italy and Romania. These results suggest that the processes that are at the basis of literacy acquisition are acquired with greater difficulty in children learning Flemish than in children acquiring Italian or Romanian, in line with previous studies (Landerl et al., 2019; Tiron \& Ghergut, 2019, for a review; Ziegler et al., 2010; Ziegler \& Goswami, 2005). In contrast with our hypothesis, the performance of the children in the grapho-motor task was not similar across countries. Tests showed that the Belgian children scored significantly higher in this task as compared to both Italian and Romanian children. These results might be explained by preschool curriculum differences. It is possible that Belgian preschoolers take part in more activities focused on the development of visual-motor skills than Italian or Romanian children do.

To test whether the activities carried out at preschool could also influence early literacy acquisition processes, in line with Inoue et al. (2020), we compared the performance of the children in Italy and in Romania in the same early literacy tasks. While Italy and Romania share similarities in the orthographic system consistency of their languages, only the preschools in Romania are instructed to present children with specific activities that are aimed at supporting their literacy development. These activities are likely to enhance the children's early literacy development and should correspond to higher performance in early literacy tasks overall at preschool. Results showed that the children in Romania scored higher than those in Italy in the lexical production task and in the Talk assessment overall. Because the Italian and Romanian languages are similar in terms of orthographic consistency, these 
findings indicate that factors such as curriculum practices at preschool may also come into play and affect the children's early literacy acquisition trajectories. The use of more indirect early literacy instruction through activities such as book reading and games (as it happens in Italy) may not adequately support the children's language and literacy development. However, it should be noted that curriculum practices were only treated as latent variables in the present study; our results will have to be confirmed by future research directly measuring these variables before conclusions can be drawn (Campbell et al., 2001; Graue, Clements, Reynolds, \& Niles, 2004; Nelson, Brenner, \& Gonzalez, 2003).

Our second aim was to assess whether early literacy skills (as measured using the Talk, RAN, and grapho-motor tasks) could predict reading and writing performance nine months later, at primary school. Based on previous studies (Catts et al., 1999; Dickinson et al., 2010; Kendeou, Van Den Broek, White, \& Lynch, 2009), we expected this to be the case, albeit with possible differences between countries. Tests showed significant correlations, in Italy and in Belgium, between the children's early literacy skills at preschool and their reading and writing abilities at the end of first grade. More precisely, in both countries the children who had higher scores in the Talk subtests (which tested phonological, lexical, and morphosyntactic abilities) at preschool later exhibited better writing performance; those who performed better in the automatized naming task (which tests the ability to retrieve words and the strength of word-object associations) at preschool later demonstrated better reading skills; finally, the children who demonstrated better visual-manual coordination in the grapho-motor task later showed better reading skills at the end of first grade. Interestingly, only in Belgium both naming and visual-manual coordination skills were associated with better writing skills at the end of first grade, which possibly suggests that these skills may particularly come into play in the development of a language that has a more opaque orthographic system. No significant associations emerged for the Romanian children. However, the lack of significant correlations between our early measures and later reading and writing performance in this group may simply be due to the fact that the literacy skills in the Romanian group were assessed using reading and writing tests that were different from those of the other two countries. While the tests used in Italy and Belgium were more similar and asked participants to read a series of words, those used in Romania required children to name letters. This element, which may have affected the children's accuracy and times, suggests that designing word reading and writing tests for Romanian children may be of help in testing their skills more accurately.

To further investigate whether and which of our early measures was predictive of the children's later reading and writing skills in each country, we also ran multiple linear regressions. We hypothesized that the Talk assessment (investigating several domains of the literacy prerequisites) would predict later reading and writing performance, although with potential differences across countries due to factors such as orthographic transparency and preschool curriculum. In line with our hypotheses, our results showed that the children's early literacy scores at preschool predicted their reading and writing outcomes at the end of first grade; however, the influence of these predictors differed across countries. Interestingly, although the total proportion of variance explained by each model was limited, the three early literacy variables together significantly predicted the children's reading skills in Romania, the children's writing skills in Belgium, and both reading and writing in Italy. While no single skill had a significant effect on reading for Romania, the graphomotor scores and the total Talk scores were significant predictors of the writing skills of the Belgian and Italian children, respectively, at primary school. The demonstrated role of several language components (as measured using the Talk assessment) in predicting reading and writing skills in first grade in Italy supports the idea that components such as phonological awareness and oral language skills are extremely important to achieve literacy 
(Lonigan et al., 2000; Sènèchal et al., 2006). The seeming absence of a significant link between the early language components measured by the Talk assessment and later literacy in Flemish may be related to its orthographic system and to the potentially more complex processes that underlie reading and writing acquisition in languages with opaque orthographies. In contrast with our expectations, the Talk assessment was not predictive of the Romanian children's later reading and writing performance; however, these results may once again be linked to the specific tests used in this sample. The use of different tests across countries is a limitation of the present study, because it prevented us from testing all children using the instruments that tap into and measure in the same way the same skills.

In sum, the present study shows that the combined use of the Talk assessment and of the RAN and grapho-motor tasks provides a significant index of the Italian, Romanian, and Belgian children's literacy skills at primary school, especially as regards writing. Our findings also show that early literacy skills progress with different speed in countries that differ for linguistic and educational variables such as orthographic transparency and preschool curriculum. However, the role of these variables in affecting literacy acquisition trajectories needs to be further investigated and confirmed by other studies employing different tests, languages, and participants, before generalizations can be drawn. As mentioned above, the reading and writing tests used in the three countries for the present study were different, which may affect the significance of the results and of the relationship between early literacy precursors and later reading and writing skills. The limited number of participants may also have affected our findings: for practical reasons only a few schools were selected for each country; moreover, a few of the Italian and Belgian children could not be tested again at the end of first grade, thus significantly reducing the final participants' sample in the analysis of the relationship between early and later literacy measures. These factors do not grant us the opportunity to draw general conclusions that may apply to a wider portion of students from the same country or speaking the same language, even less to infer the validity of the Talk assessment for other European countries not involved in the project.

Notwithstanding, the present study offers preliminary findings that may help broaden our knowledge about literacy acquisition. First, it provides results about the validity of new and multidimensional assessment tool, the 'Talk', targeted at measuring preschoolers' phonological, lexical, and morphosyntactic skills. This tool could have important implications for supporting teachers' work in school. Although it requires individual - and not in class - testing, the Talk assessment provides a quick, easy-to-administer, useful, and fun offline measure of the preschool children's language competences; this may, in turn, help teachers and educators identify language difficulties, offer better-targeted support, and plan ad hoc intervention programs to remediate fragilities. Second, the study provides new evidence of how the relationship between early literacy skills and literacy acquisition differs across languages with more or less transparent systems and thus contributes to the improvement of the knowledge that is necessary to design tests that can be applied to multiple countries and contexts. Finally, the findings of the present study may help inform teachers on how curricula in the transition period between preschool and primary school affect literacy acquisition, with possibly positive consequences for good practice and for educational systems and curricula design.

Funding Open access funding provided by Università degli Studi di Verona within the CRUI-CARE Agreement. The project «TALK», with number 2017-1-IT02-KA201-036595, under the Erasmus + Programme, was funded with support from the European Commission. The European Commission's support for the production of this publication does not constitute an endorsement of the contents, which reflect the views only of the authors, and the Commission cannot be held responsible for any use which may be made of the information contained therein. 
Open Access This article is licensed under a Creative Commons Attribution 4.0 International License, which permits use, sharing, adaptation, distribution and reproduction in any medium or format, as long as you give appropriate credit to the original author(s) and the source, provide a link to the Creative Commons licence, and indicate if changes were made. The images or other third party material in this article are included in the article's Creative Commons licence, unless indicated otherwise in a credit line to the material. If material is not included in the article's Creative Commons licence and your intended use is not permitted by statutory regulation or exceeds the permitted use, you will need to obtain permission directly from the copyright holder. To view a copy of this licence, visit http://creativecommons.org/licenses/by/4.0/.

\section{References}

Araújo, S., Reis, A., Petersson, K., \& Faísca, L. (2015). Rapid automatized naming and reading Performance: A meta-analysis. Journal of Educational Psychology, 107, 868-883. https://doi.org/10.1037/ edu0000006.

Aro, M., \& Wimmer, H. (2003). Learning to read: English in comparison to six more regular orthographies. Applied Psycholinguistics, 24, 621-635. https://doi.org/10.1017/S0142716403000316.

Bar-Kochva, I., \& Nevo, E. (2019). The relations of early phonological awareness, rapid naming and speed of processing with the development of spelling and reading: A longitudinal examination. Journal of Research in Reading, 42(1), 97-122. https://doi.org/10.1111/1467-9817.12242.

Bodea Haţegan, C., Talaş, D., \& Trifu, R. Probe for assessing reading and writing skills at the end of preparing grade. ASTTLR, Cluj-Napoca (in press).

Bodea Haţegan, C., \& Talaş, D. (2014). Verbal Fluency. Theoretical Directions and practical approaches. . Presa Universitară Clujeană Press.

Brizzolara, D., Chilosi, A., Cipriani, P., Di Filippo, G., Gasperini, F., Mazzotti, S., \& Zoccolotti, P. (2006). Do Phonologic and Rapid Automatized Naming Deficits Differentially Affect Dyslexic Children With and Without a History of Language Delay? A Study of Italian Dyslexic Children. Cognitive and Behavioral Neurology, 19, 141-149. https://doi.org/10.1097/01.wnn.0000213902.59827.19.

Brus, T., \& Voeten, M. (1999). One-minute-test Form A and B (OMT). . Harcourt Test Publishers.

Cain, K., \& Oakhill, J. (2011). Matthew Effects in Young Readers: Reading Comprehension and Reading Experience Aid Vocabulary Development. Journal of Learning Disabilities, 44, 431-443. https://doi. org/10.1177/0022219411410042.

Campbell, R., Pungello, E. P., Miller-Johnson, S., Burchinal, M. R., \& Ramey, C. T. (2001). The development of cognitive and academic abilities: Growth curves from an early childhood educational experiment. Developmental Psychology, 27, 231-242. https://doi.org/10.1037/0012-1649.37.2.231.

Caravolas, M., Lervåg, A., Defior, S., Málková, G. S., \& Hulme, C. (2013). Different patterns, but equivalent predictors, of growth in reading in consistent and inconsistent orthographies. Psychological Science, 24, 1398-1407. https://doi.org/10.1177/0956797612473122.

Caravolas, M., Volín, J., \& Hulme, C. (2005). Phoneme awareness is a key component of alphabetic literacy skills in consistent and inconsistent orthographies: Evidence from Czech and English children. Journal of Experimental Child Psychology, 92, 107-139. https://doi.org/10.1016/j.jecp.2005.04.003.

Catts, H. W., Fey, M. E., Zhang, X., \& Tomblin, J. B. (1999). Language basis of reading and reading disabilities: Evidence from a longitudinal investigation. Scientific Studies of Reading, 3, 331-361. https:// doi.org/10.1207/s1532799xssr0304_2.

Connor, C. M., Morrison, F. J., \& Slominski, L. (2006). Preschool instruction and children's emergent literacy growth. Journal of Educational Psychology, 98, 665-689. https://doi.org/10.1037/0022-0663. 98.4.665.

Connor, C. M., Son, S.-H., Hindman, A. H., \& Morrison, F. J. (2005). Teacher qualifications, classroom practices, family characteristics, and preschool experience: Complex effects on first graders' vocabulary and early reading outcomes. Journal of School Psychology, 43, 343-375. https://doi.org/10.1016/j. jsp.2005.06.001.

Daffern, T. (2018). Innovative linguistic inquiries in the primary classroom. Practical Literacy, 23(1), 10-13.

Deloof, G. (2006). Student tracking system LVS-VCLB Spelling Tests 1-6. . Garant.

Dickinson, G., Golinkoff, R. M., \& Hirsh-Pasek, K. (2010). Speaking out for language: Why language is central to reading development. Educational Researcher, 39, 305-310. https://doi.org/10.3102/00131 89X10370204.

Dinehart, L. H. (2015). Handwriting in early childhood education: Current research and future implications. Journal of Early Childhood Literacy, 15, 97-118. https://doi.org/10.1177/1468798414522825. 
Dunn, L. M., \& Dunn, L. M. (1981). Peabody Picture Vocabulary Test-Revised. American Guidance Service Inc.

Frankenburg, W. K., \& Dodds, J. B. (2010). DENVER-II, Denver Developmental Screening Test by Iliescu, D., Mitrofan, N., Trans. Cluj-Napoca: Editura Sinapsis (Original work published 1967).

Goswami, U. (2014). Child Psychology-A Very Short Introduction. . Oxford University Press.

Graue, E., Clements, M. A., Reynolds, A. J., \& Niles, M. D. (2004). More than teacher directed or child initiated: Preschool curriculum type, parent involvement, and children's outcomes in the Child-Parent Centers. Education Policy Analysis Archives, 12(72), 1-40. https://doi.org/10.14507/epaa.v12n72.2004.

Gray, S., Fox, A., Green, S., Alt, M., Hogan, T., Petscher, Y., \& Cowan, N. (2019). Working memory profiles of children with dyslexia, developmental language disorder, or both. Journal of Speech, Language, and Hearing Research, 62, 1839-1858. https://doi.org/10.1044/2019_JSLHR-L-18-0148.

Inoue, M., Manolitsis, G., de Jong, P. F., Landerl, K., Parrila, R., \& Georgiou, G. K. (2020). Home literacy environment and early literacy development across languages varying in orthographic consistency. Frontiers in Psychology, 11, 1923-1923. https://doi.org/10.3389/fpsyg.2020.01923.

JASP Team (2019). JASP (Version 0.11.1) [Computer software].

Justice, L., Invernizzi, M., \& Meier, J. (2002). Designing and implementing an early literacy screening protocol: Suggestions for the speech-language pathologist. Language, Speech, and Hearing Services in Schools, 33, 84-101. https://doi.org/10.1044/0161-1461(2002/007).

Kendeou, P., Van Den Broek, P., White, M., \& Lynch, J. (2009). Predicting reading comprehension in early elementary school: The independent contributions of oral language and decoding skills. Journal of Educational Psychology, 101, 765-778. https://doi.org/10.1037/a0015956.

Kirby, J., Georgiou, G., Martinussen, R., \& Parrila, R. (2010). Review of naming speed and reading: From prediction to instruction. Reading Research Quarterly, 45, 341-362. https://doi.org/10.1598/RRQ.45.3.4.

Landerl, K., Freudenthaler, H. H., Heene, M., De Jong, P. F., Desrochers, A., Manolitsis, G., \& Georgiou, G. K. (2019). Phonological awareness and rapid automatized naming as longitudinal predictors of reading in five alphabetic orthographies with varying degrees of consistency. Scientific Studies of Reading, 23, 220-234. https://doi.org/10.1080/10888438.2018.1510936.

Lervåg, A., Bråten, I., \& Hulme, C. (2009). The cognitive and linguistic foundations of early reading development: A Norwegian latent variable longitudinal study. Developmental Psychology, 45, 764781. https://doi.org/10.1037/a0014132.

Lonigan, C. J., Burgess, S. R., \& Anthony, J. L. (2000). Development of Emergent Literacy and Early Reading Skills in Preschool Children: Evidence from a Latent-Variable Longitudinal Study. Developmental Psychology, 36, 596-613. https://doi.org/10.1037/0012-1649.36.5.596.

Martini, A. (1995). Learning, reading and writing disorders. . Del Cerro.

McIlraith, A. L., \& Language and Reading Research Consortium (LARRC). (2018). Predicting word reading ability: A quantile regression study. Journal of Research in Reading, 41, 79-96. https://doi. org/10.1111/1467-9817.12089.

Melby-Lervåg, M., Lyster, S. A. H., \& Hulme, C. (2012). Phonological skills and their role in learning to read: A meta-analytic review. Psychological Bulletin, 138, 322-352. https://doi.org/10.1037/a0026744.

National Early Literacy Panel (2008). Developing early literacy: Report of the national early literacy panel. Resource Document. Retrieved from https://lincs.ed.gov/publications/pdf/NELPReport09.pdf

National Institute of Child Health and Human Development Early Child Care Research Network. (2005). Pathways to reading: The role of oral language in the transition to reading. Developmental Psychology, 41, 428-442. https://doi.org/10.1037/0012-1649.41.2.428.

Nelson, J. R., Benner, G. J., \& Gonzalez, J. (2003). Learner characteristics that influence treatment effectiveness of early literacy interventions: A meta-analytic review. Learning Disabilities Research and Practice, 18, 255-267. https://doi.org/10.1111/1540-5826.00080.

Norton, E., \& Wolf, M. (2012). Rapid automatized naming (RAN) and reading Fluency: Implications for understanding and treatment of reading disabilities. Annual Review of Psychology, 63, 427-452. https://doi.org/10.1146/annurev-psych-120710-100431.

Pennington, B. F., Cardoso-Martins, C., Green, P. A., \& Lefly, D. L. (2001). Comparing the phonological and double deficit hypotheses for developmental dyslexia. Reading and Writing: An Interdisciplinary Journal, 14, 707-755. https://doi.org/10.1023/A:1012239018038.

Patel, T. K., Snowling, M. J., \& De Jong, P. F. (2004). A cross-linguistic comparison of children learning to read in English and Dutch. Journal of Educational Psychology, 96, 785-797. https://doi.org/10. 1037/0022-0663.96.4.785.

Quinn, J., Wagner, R., Petscher, Y., \& Lopez, D. (2015). Developmental Relations Between Vocabulary Knowledge and Reading Comprehension: A Latent Change Score Modeling Study. Child Development, 86, 159-175. https://doi.org/10.1111/cdev.12292. 
Reise, S. P. (2012). The rediscovery of bifactor measurement models. Multivariate Behavioral Research, 47, 667-696. https://doi.org/10.1080/00273171.2012.715555.

Reise, S. P., Bonifay, W. E., \& Haviland, M. G. (2013). Scoring and modeling psychological measures in the presence of multidimensionality. Journal of Personality Assessment, 95, 129-140. https://doi.org/10. 1080/00223891.2012.725437.

Schlichting, L. (2005). Peabody picture vocabulary test-III-NL. . Hartcourt Assessment BV.

Seymour, P. H., Aro, M., \& Erskine, J. M. (2003). Foundation literacy acquisition in European orthographies. British Journal of Psychology, 94, 143-174. https://doi.org/10.1348/000712603321661859.

Sénéchal, M., Ouellette, G., \& Rodney, D. (2006). The misunderstood giant: On the predictive role of early vocabulary to future reading. In D. K. Dickinson \& S. B. Neuman (Eds.), Handbook of early literacy research. (2nd ed., pp. 173-184). Guilford Press.

Snowling, M. J., Gallagher, A., \& Frith, U. (2003). Family risk of dyslexia in continuous: Individual differences in precursors of reading skill. Child Development, 74, 358-373.

Stella, G., Pizzioli, C., \& Tressoldi, P. E. (2000). Peabody Picture Vocabulary Test. . Torino: Omega.

Tiron, G., \& Ghergut, A. (2019). The predictors of dyslexia in a regular orthography. psychology series. (Vol. 28, pp. 67-90). Annals of AII Cuza University.

Van den Bos, K., Spelberg, H., Scheepstra, A., \& de Vries, J. (1999). The Klepel Non-word-reading test. Form $A$ and B. . Swets Test Publishers.

Wilcox, M. J., Gray, S., \& Reiser, M. (2020). Preschoolers with Developmental Speech and/or Language Impairment: Efficacy of the Teaching Early Literacy and Language (TELL) Curriculum. Early Childhood Research Quarterly, 51, 124-143. https://doi.org/10.1016/j.ecresq.2019.10.005.

Wilcox, M. J., Gray, S. I., Guimond, A. B., \& Lafferty, A. E. (2011). Efficacy of the TELL language and literacy curriculum for preschoolers with developmental speech and/or language impairment. Early Childhood Research Quarterly, 26, 278-294. https://doi.org/10.1016/j.ecresq.2010.12.003.

Wimmer, H., Mayringer, H., \& Landerl, K. (2000). The double-deficit hypothesis and difficulties in learning to read a regular orthography. Journal of Educational Psychology, 92, 668-680. https://doi.org/10. 1037/0022-0663.92.4.668.

Zemlock, D., Vinci-Booher, S., \& James, K. (2018). Visual-motor symbol production facilitates letter recognition in young children. Reading and Writing, 31, 1255-1271. https://doi.org/10.1007/s11145-018-9831-z.

Ziegler, J. C., Bertrand, D., Tóth, D., Csépe, V., Reis, A., Faísca, L., \& Blomert, L. (2010). Orthographic depth and its impact on universal predictors of reading: A cross-language investigation. Psychological science, 21, 551-559. https://doi.org/10.1177/0956797610363406.

Ziegler, J. C., \& Goswami, U. (2005). Reading acquisition, developmental dyslexia, and skilled reading across languages: A psycholinguistic grain size theory. Psychological Bulletin, 131(1), 3-29. https:// doi.org/10.1037/0033-2909.131.1.3.

Publisher's Note Springer Nature remains neutral with regard to jurisdictional claims in published maps and institutional affiliations.

\section{Authors and Affiliations}

\section{Marinella Majorano ${ }^{1} \cdot$ Tamara Bastianello' $^{1} \cdot$ Carolina Bodea-Hategan $^{2}$. Patrizia Fantuzzi ${ }^{3}$. Giulia Fontana ${ }^{3}$. Eddy Hoste ${ }^{4}$. Marco Lombardi ${ }^{4}$. An Standaert ${ }^{4}$. Dorina Talas $^{2} \cdot$ Raluca Trifu $^{5} \cdot$ Lisa Vescogni $^{3} \cdot$ Valentina Persici $^{1}$ (D)}

1 Department of Human Sciences, University of Verona, Via San Francesco 22, 37129 Verona, Italy

2 Department of Special Education, Faculty of Psychology and Education Sciences, Babeș-Bolyai University, Cluj-Napoca, Romania

3 Progetto Crescere Association, Reggio Emilia, Italy

4 HOGENT, Gent, Belgium

5 Department of Medical Education, University of Medicine and Pharmacy "Iuliu-Hațieganu", Cluj-Napoca, Romania 